\title{
Development of antagonistic bacteria for field control of fire blight
}

\author{
$\underline{\text { Christine Hübert }^{1}}{ }$ Helmut Junge $^{2}$, Kristin Dietel $^{2}$, Helmut Junge ${ }^{2}$, Annette Wensing ${ }^{1}$, \\ Wilhelm Jelkmann ${ }^{1}$ \\ ${ }^{1}$ Julius Kühn-Institut, Institute for Plant Protection in Fruit Crops and Viticulture, Dossenheim \\ ${ }^{2}$ ABiTEP GmbH, Berlin \\ Email of corresponding author: christine.huebert@jki.bund.de
}

Application of antagonists is considered a possible alternative towards use of antibiotics like streptomycin in fire blight control. Mechanisms of biological control by bacterial antagonists are diverse and can base on competition or include more direct means like toxin production.

The Gram-negative bacterium Erwinia tasmaniensis is closely related to the fire blight pathogen Erwinia amylovora. It shares not only many physiological traits, but is also well adapted to the fire blight habitat. Whereas $E$. tasmaniensis does not produce any toxins against $E$. amylovora, an inhibition due to competition for nutrients and/or living space between both bacteria is conceivable.

The Gram-positive bacterium Bacillus amyloliquefaciens is considered a classical soil habitant. While it is not well adapted to survival on aerial plant surfaces, it possesses interesting antagonistic features due to the production of a broad spectrum of secondary metabolites which are partly toxic for $E$. amylovora.

In this project we compare performance of both antagonists in a number of laboratory setups and in field trials.
Co-cultivation of E. tasmaniensis and a luminescent reporter strain of E. amylovora as an indicator strain revealed reduced pathogen growth, but no inhibition after application of supernatants. We also investigated various Bacillus isolates for their effect on E. amylovora. Application of supernatants revealed promising results in growth inhibition of the pathogen. However, efficiency of secondary metabolites depends on medium and growth phase. The effects were visible in dual-culture assays as well as in agar diffusion analysis. In detached-flower assays reduction in symptom development could be observed after application of antagonists, but the results still revealed considerable fluctuations. We also compared population development on inoculated flowers.

Nevertheless, for field operation any antagonist has to be conserved for long term storage and formulations have to become active within a short time frame after application. A combination of both metabolite formulations and antagonists might help to cover part of this problem and should be tested in further examinations. 